\section{Five reasons to choose new corporate}

As the newest kid on the corporate block, Dental Partners is changing the face of the sector by putting its clinical teams at the centre of decision-making.

As more and more practices and clinicians join its ever-expanding network, it has spelled out the top five reasons why working with Dental Partners is a smart decision.

1. Fastest growing UK dental group - its network is quickly expanding. Since the start of 2018, it has acquired 29 practices across the UK, successfully positioning itself in the top six UK dental groups

2. Best place to work - its simple but effective formula is that it wants to be the best place to work, in turn offering the best choice and treatment for patients. It brings a refreshing ethos to UK dentistry building a supportive network for clinicians looking for the stability of a corporate position but without the constraints normally associated with this working environment

3. Clinical freedom - it believes it is the staff in the practices who know how they are best run - and Dental Partners is not in the business of telling you what to do. It provides all the assistance needed in terms of equipment, practice marketing and compliance, so you can concentrate on retaining complete clinical freedom

4. Career development - it helps the whole team realise their career and lifestyle ambitions with fantastic training and charitable opportunities for both personal and professional development

5. Social conscience - its ethos is to create pleasant, diverse and respectful workplaces with a social conscience. It says it likes its staff to build on each other's unique attributes and reflect the communities they serve.

More information is available by visiting www.dentalpartners.co.uk or by emailingcontact@dentalpartners.co.uk.

\section{Low investment, high protection}

All equipment needs to be kept clean to function and prevent cross infection and Dürr Dental has a full range of disinfection products manufactured to the highest industry standards.

The company says their range does not just protect against bacteria and fungi, it is also fully virucidal, meaning it destroys all viruses, both enveloped and non-enveloped, such as polio and the Norovirus.

The company recently launched a Hygiene Starter Pack, so that those unfamiliar with the superior functionality of Durr's disinfection range, can try it at a substantially reduced price.

The pack contains their ID 212 Instrument Cleaner, MD 555 Special Cleaner for Suction Units, HD 410 Hand Disinfectant and FD 312 Surface Disinfectant Wipes. It retails at $£ 48$ - a saving of $£ 50$ off the normal price of $£ 98$.

These are just examples from

Dürr's comprehensive range. All are conveniently colour coded to identify each products application - blue for instruments, green for surfaces, pink for skin and hands, and yellow for special areas such as suction systems and amalgam separators. For more information contact Dürr Dental on 01536 526740 .

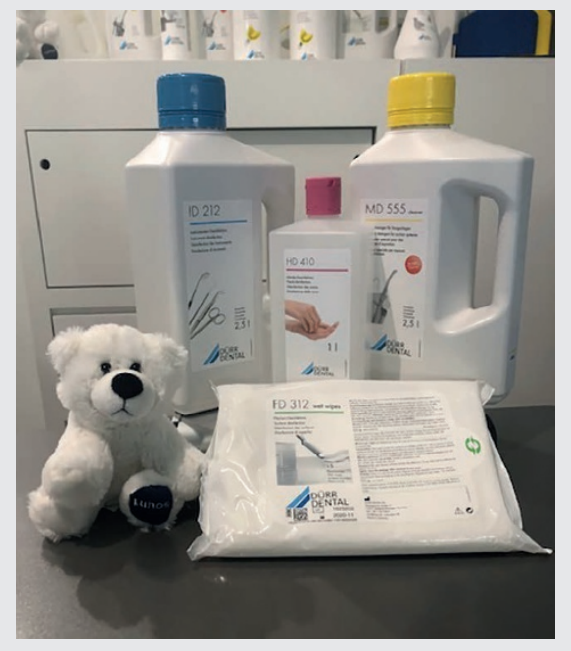

\title{
Perfect for posterior cases - and an alternative to amalgam
}

To provide natural-looking restorations in the posterior region, you need a composite you can trust. Make sure you get the results you require by choosing Filtek One bulk fill restorative from $3 \mathrm{M}$ Oral Care.

Able to create excellent restorations ${ }^{1}$ in posterior regions, ${ }^{2}$ this restorative comes in five shades that have been designed to provide natural-looking results. ${ }^{3}$

Providing easy sculpting and shaping, ${ }^{4}$ the restorative material also helps professionals to create restorations with speed and simplicity ${ }^{5}$ resulting in faster treatments for patients.
A straight-forward, aesthetic solution, discover more benefits of Filtek One bulk fill restorative by contacting $3 \mathrm{M}$ Oral Care.

For more information, call 0800626578 or visit www.3M.co.uk/Dental.

1. $3 \mathrm{M}$ Oral Care Internal Data. Excellent restorations. Claim 6783 (2016).

2. $3 \mathrm{M}$ Oral Care Internal Data. Excellent restorations in posterior. Claim 6784 (2016).

3. $3 \mathrm{M}$ Oral Care Internal Data. Shades to suit posterior. Claim 6772 (2016)

4. 3M Oral Care Internal Data. Easy sculpting and shaping. Claim 6761 (2016)

5. $3 \mathrm{M}$ Oral Care Internal Data. Speed and simplicity. Claim 6065 (2014).

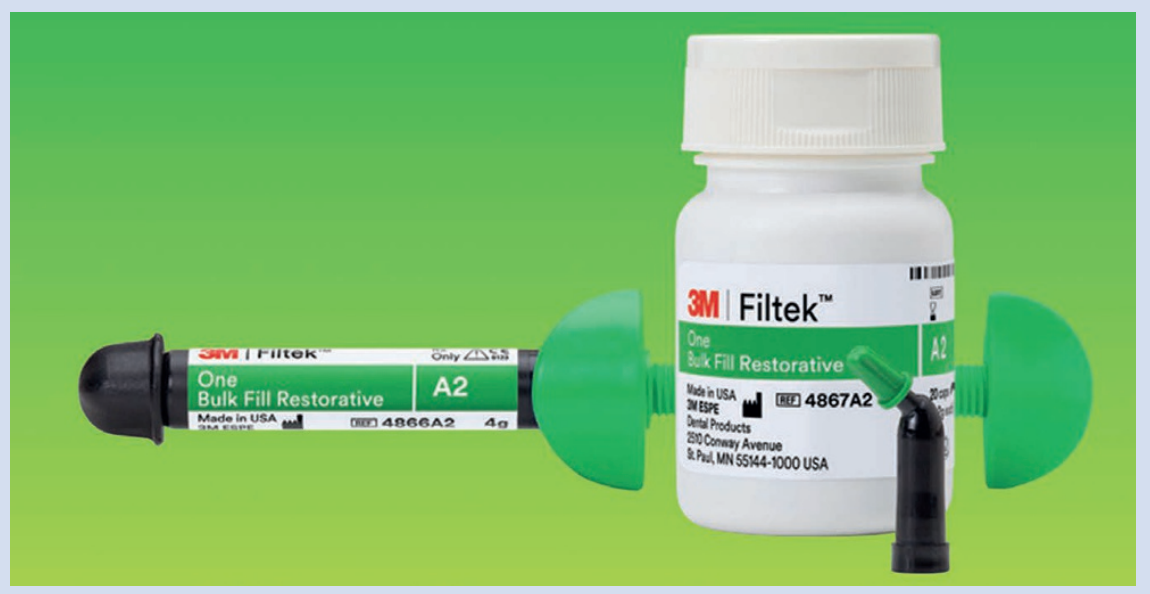

